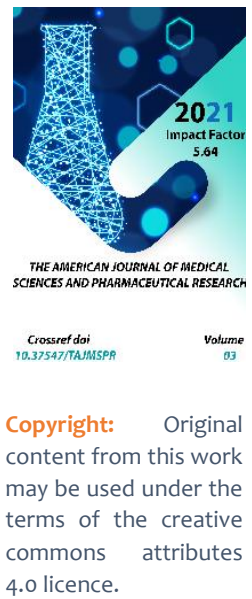

\title{
Experience Of Application Of A New Hemostatic Agent "Gemogubka" In The Prevention Of Bleeding From The Gall Bladder Body After Traditional Cholecystectomy
}

\author{
O.U. Rakhimov \\ Tashkent Pediatric Medical Institute, Uzbekistan
}

\section{ABSTRACT}

Purpose of the study. To assess the effectiveness of the use of hemostatic agent "GEMOGUBKA" for the prevention of bleeding from the bed of the gallbladder during traditional cholecystectomy. Methods. The study included 88 patients operated for acute calculous cholecystitis. Depending on the method of bleeding hemostasis, all patients were divided into 2 groups: in the study group $(n=43)$, after cholecystectomy, 250-300 mg of "GEMOGUBKA" in the form of a fine powder was applied to the gallbladder bed for hemostasis; in the control group ( $n=45)$, after cholecystectomy, hemostasis was carried out by electrocoagulation of the gallbladder bed with a monopolar electrode. All patients in the postoperative period underwent control-dynamic ultrasound examination, study of the volume and nature of the discharge from the drains, as well as a biochemical blood tests. Results. In the study group, the average duration of hemostasis with bleeding from the bladder bed was $2,3 \pm 1,3$ minutes, which is almost 2 times less than in the control group - 4,2 $\pm 1,5$ minutes. The duration of bed-days after surgery was $4,5 \pm 0,78$ days and 6,3 $\pm 2,06$ days, respectively. The duration of the presence of the drainage tubes in the abdominal cavity in the study group was 1,49 $\pm 0,88$ days, while in the control group it was $4,24 \pm 1,38$ days. The dynamics of the manifestation of cytolytic syndrome showed a low degree of intraoperative aggression during hemostasis in the study group, which significantly differed from the high rates of cytolysis in the control group. In the study group of patients, it was possible to significantly reduce the proportion of serous-hemorrhagic and hemorrhagic discharge from the drainage tube in comparison with patients in the control group. Conclusion. The use of the biocomposition in the form of the hemostatic drug "GEMOGUBKA" allowed both to reduce the duration of bleeding from the bed of the gallbladder, and the incidence of local inflammatory complications of the surgical site during traditional cholecystectomy. 


\section{KEYWORDS}

Acute cholecystitis; cholecystectomy; complications of cholecystectomy; hemostasis.

\section{INTRODUCTION}

Today, despite the large variety of the proposed methods of hemostasis, there is no common point of view regarding the method of choice for stopping parenchymal bleeding from the gallbladder bed during cholecystectomy $[1,2,3]$.

There are such traditional methods of stopping bleeding as the imposition of U-shaped sutures, tamponade with an omentum or gauze swab and electrocoagulation. The latter method has not lost its relevance today, as it provides compression of intraorgan vessels $[4,5]$. However, in cases where there is capillary, superficial bleeding, it is advisable to use alternative sparing techniques, since suturing is associated with additional damage to body tissues $[6,7,8]$.

Bleeding from the gallbladder bed can lead to an increase in the operation time, conversions, lengthening of the postoperative period, repeated operations (in $0.2-14 \%$ of cases) and in $3.4 \%$ of cases - lead to the death of the patient $[9,10]$.

An incorrectly or insufficiently treated gallbladder bed can become a source of bleeding and bile leakage both during surgery and in the postoperative period. The need to solve the listed problems is due to the rather large specific gravity of gallstone disease in the structure of the population's morbidity and the high percentage of its complications associated with the treatment of the gallbladder bed during surgical treatment [11,12].

Thus, the problem of effective intraoperative stopping of bleeding from the gallbladder bed during traditional cholecystectomy is very urgent, and in this regard, the new local hemostatic "GEMOGUBKA" is of considerable interest.

\section{PURPOSE OF THE STUDY}

To study the effectiveness of the use of a new local hemostatic agent "GEMOGUBKA" for the prevention of bleeding from the bed of the gallbladder during traditional cholecystectomy in patients with acute calculous cholecystitis.

\section{MATERIAL AND RESEARCH METHODS}

The study included 88 patients operated on for acute calculous cholecystitis from 2019 to 2020 in the surgical department of the city clinical hospital № 1 . The contingent of patients included 24 men and 64 women, whose average age was $48.88 \pm 14.57$ years.

Surgical treatment for acute destructive cholecystitis in the patients examined by us was performed on an emergency or urgent basis. Emergency operations were performed if there were signs of peritonitis or if drug therapy was ineffective within 2-3 hours. In both groups, the operation was completed with drainage of the subhepatic space with a PVC tube. In the course of surgery, patients 
often experienced relatively active, diffuse bleeding from the gallbladder bed.

Depending on the method of hemostasis of bleeding in the gallbladder bed, all observed patients were divided into 2 groups:

- In the study group ( $\mathrm{n}=43$ ), after cholecystectomy, 250-300 mg of a GEMOGUBKA in the form of a fine powder was applied to the gallbladder bed for hemostasis;

- In the control group ( $\mathrm{n}=45)$, after cholecystectomy, hemostasis was carried out by using high-frequency electricity using electrocoagulation of the gallbladder bed with a monopolar electrode.

The studied groups were comparable in terms of sex, age, severity of the condition and concomitant pathology. The average duration of gallstone disease in the main group was 3.1 \pm 2 years, and in the control group $5.2 \pm 4.3$ years. In all groups, before the operation, standard general clinical and laboratory examinations, ultrasound examinations of the abdominal cavity and kidneys were performed.

In the main group after cholecystectomy, in order to achieve hemostasis in the gallbladder bed, a new drug GEMOGUBKA was used, developed at the State Institution "RSSPMSC named after acad. V. Vakhidov jointly with the Research Institute of Polymer ChemistryPhysics of the Academy of Sciences of the Republic of Uzbekistan. The main components of the implant are: sodium carboxymethylcellulose, oxidized cellulose, nanocellulose and bound calcium ions. "GEMOGUBKA" is a powder. Figure 1 shows its microscopic structure.

The most important characteristic of hemostatic implants is the ability to adhere, that is, the adhesion of the surface layers of two dissimilar bodies brought into contact. The adhesion of the GEMOGUBKA to the wound surface provides mechanical closure of the vessel lumen, which significantly increases the effectiveness of stopping bleeding. High adhesion of the implant is due to its flexibility and moderate hydrophilicity. According to Sadykov R.A. et al. [5] the strength of adhesion of the film coating was $7.3 \pm 0.2 \mathrm{KPa}$, breaking strength $-390 \pm 4.8 \mathrm{kgf} / \mathrm{cm} 2$. The time required for hemostasis is $5.3 \pm 3.1$ minutes.

All patients in the postoperative period underwent control-dynamic ultrasound examination, measurement of the volume and nature of the drainage from the control drains. In all patients, the activity of alanine aminotransferase (ALT), aspartate aminotransferase (AST), the level of total protein and bilirubin were studied in the venous blood 24 hours after the operation, as well as after 5 days.

The research results were subjected to statistical processing using the program (Microsoft Excel). To describe normally distributed parameters, we used the arithmetic mean and standard deviation of the arithmetic mean. To identify the relationships, the method of correlation analysis was used, which includes both the assessment of the Spearman correlation coefficient $(r)$ and the level of its significance $(p)$. Differences were considered statistically significant at $p<0.05$.

\section{RESULTS AND DISCUSSION}

All patients underwent upper midline laparotomy from the xiphoid process to the umbilicus under endotracheal anesthesia. In the main group of patients, a monopolar mode of electrosurgical coagulation with subserous 
separation of the gallbladder from the liver parenchyma was performed with preliminary hydraulic dissection of the serous membrane of the gallbladder with novocaine solution, then coagulation of the gallbladder bed was performed for the purpose of hemostasis.

In the control group, 7 (15.6\%) patients due to technical difficulties during operations (perivesicular infiltrate against the background of destructive calculous cholecystitis, pronounced adhesion process in the perivesicular space,) bleeding from the gallbladder bed, after repeated unsuccessful attempts at hemostasis, was It was stopped by the imposition of a gauze swab in the gallbladder bed, and in 1 (2.2\%) patient by suturing the gallbladder bed with its intrahepatic location.

It should be noted that in the control group, additional and excessive coagulation of the gallbladder bed during the operation often did not give the desired hemostatic effect; it created an additional zone of coagulation necrosis, which in the postoperative period served as a source of hyperthermia and a substrate for purulent-inflammatory processes.

Table 1.

Indicators of a biochemical blood test before and after traditional cholecystectomy.

\begin{tabular}{|c|c|c|c|c|}
\hline \multirow{2}{*}{ Indicators } & $\begin{array}{c}\text { Comparative } \\
\text { groups }\end{array}$ & $\begin{array}{c}\text { Before } \\
\text { operation }\end{array}$ & After operation & $\begin{array}{c}\text { Validity of } \\
\text { differences }(\mathrm{p})\end{array}$ \\
\hline \multirow{2}{*}{$\begin{array}{c}\text { Bilirubin, } \\
\text { Mcmol/I }\end{array}$} & Study & $13,78 \pm 1,41$ & $15,57 \pm 2,12^{* \wedge}$ & $<0,05$ \\
\cline { 2 - 5 } & Control & $13,66 \pm 2,95$ & $17,62 \pm 4,24^{*}$ & $<0,05$ \\
\hline \multirow{2}{*}{ ALT, U/I } & Study & $28,65 \pm 3,53$ & $35,73 \pm 3,05^{* \wedge}$ & $<0,05$ \\
\cline { 2 - 5 } & Control & $26,84 \pm 4,24$ & $38 \pm 0,7^{*}$ & $<0,05$ \\
\cline { 2 - 5 } AST, U/I & Study & $29,84 \pm 4,95$ & $34,27 \pm 3,87^{* \wedge}$ & $<0,05$ \\
\cline { 2 - 5 } & Control & $29,89 \pm 2,12$ & $36,78 \pm 3,78^{*}$ & $<0,05$ \\
\hline \multirow{2}{*}{ Total protein, g/l } & Study & $70,2 \pm 1,08$ & $68,7 \pm 0,47^{\wedge}$ & $<0,05$ \\
\cline { 2 - 5 } & Control & $66,2 \pm 0,44$ & $63,9 \pm 0,67$ & $<0,05$ \\
\hline
\end{tabular}

(* differences in comparison with indicators before surgery are statistically significant $(p<0.05) ;)$

( $\wedge$ differences in comparison with the indicators of the control group are statistically significant $(p<0.05) ;)$

In the main group, the average duration of hemostasis with bleeding from the bed of the bladder was $2.3 \pm 1.3$ minutes, which is almost 2 times less than in the control group - $4.2 \pm 1.5$ minutes $(p<0.05)$. The total duration of surgery also changed commensurately, which was $76.16 \pm 22.14$ minutes in the study groups: in the main group it was $76.16 \pm 22.14$ minutes, and in the control group it was $92.22 \pm 30.79$ minutes ( $p<0.05)$, respectively. The duration of bed-days after surgery was $4.5 \pm 0.78$ days and $6.3 \pm 2.06$ days, respectively.

In $7(15.5 \%)$ patients of the control group, a gauze swab was used for hemostasis. Removal of the tampon was carried out usually on the 5- 
6th day, and the drainage tube was removed 12 days after the removal of the tampon. An ultrasound examination of the subhepatic space for the presence of effusion was mandatory. The wound channel of the tampon was sanitized with an antiseptic and Levomekol ointment. In the group of patients with tamponing of the gallbladder bed, the average length of hospital stay was $9.3 \pm 2.2$ days.
In the control group, in $1(2.2 \%)$ patient with acute cholecystitis and severe concomitant pathology, urgently operated on, the duration of treatment was 16 days due to prolonged bile flow along the drainage from the subhepatic space, which stopped on day 9, the drainage was removed on 11 days, discharged on 16 days. The duration of bleeding in this patient was 5 days. On the 5th day, no erythrocytes were found in the discharge from the drainage.

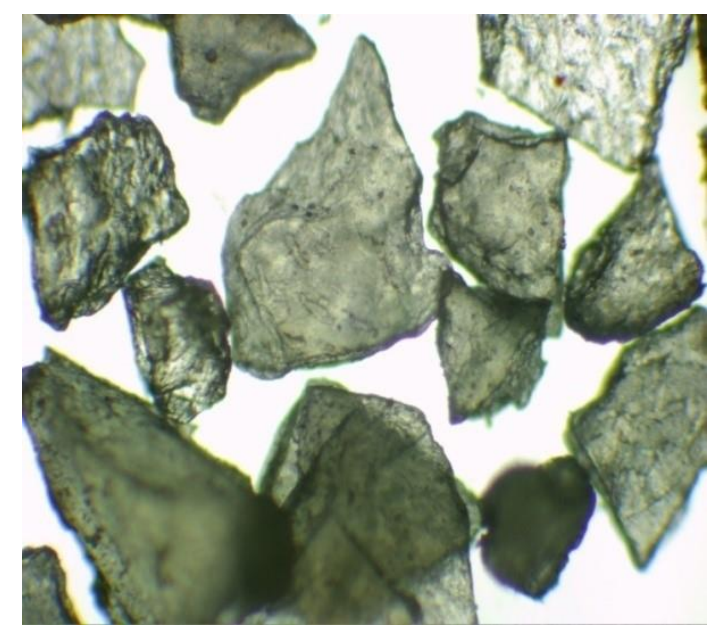

Figure 1. Microscopic structure of the "GEMOGUBKA".

To substantiate the quality of local hemostasis when using GEMOGUBKA, the duration of drainage of the subhepatic space was investigated, which was a mandatory stage of surgical intervention. The duration of the stay of the drainage tubes in the abdominal cavity in the main group was $1.49 \pm 0.88$ days, and in the control group - $4.24 \pm 1.38$ days $(p<0.05)$. In 32 (75\%) patients of the main group, the drainage from the subhepatic space was removed 1-2 days after surgery.

The interesting dynamics of the manifestation of cytolytic syndrome (the curve of the rise in the level of transaminases was determined according to the study protocol on day 1 of the po period) made it possible to conclude about a low degree of intraoperative aggression during hemostasis in the main group, which significantly differed from the high rates of cytolysis in the control group (up to $3-4$ norms in comparison with $1.5-2$ norms in the main group ( $p<0.05)$ ), where traditional methods of hemostasis of the gallbladder bed were used. Let us dwell in more detail on the analysis of biochemical blood parameters, the values of which before and after traditional cholecystectomy are shown in Table 1. 


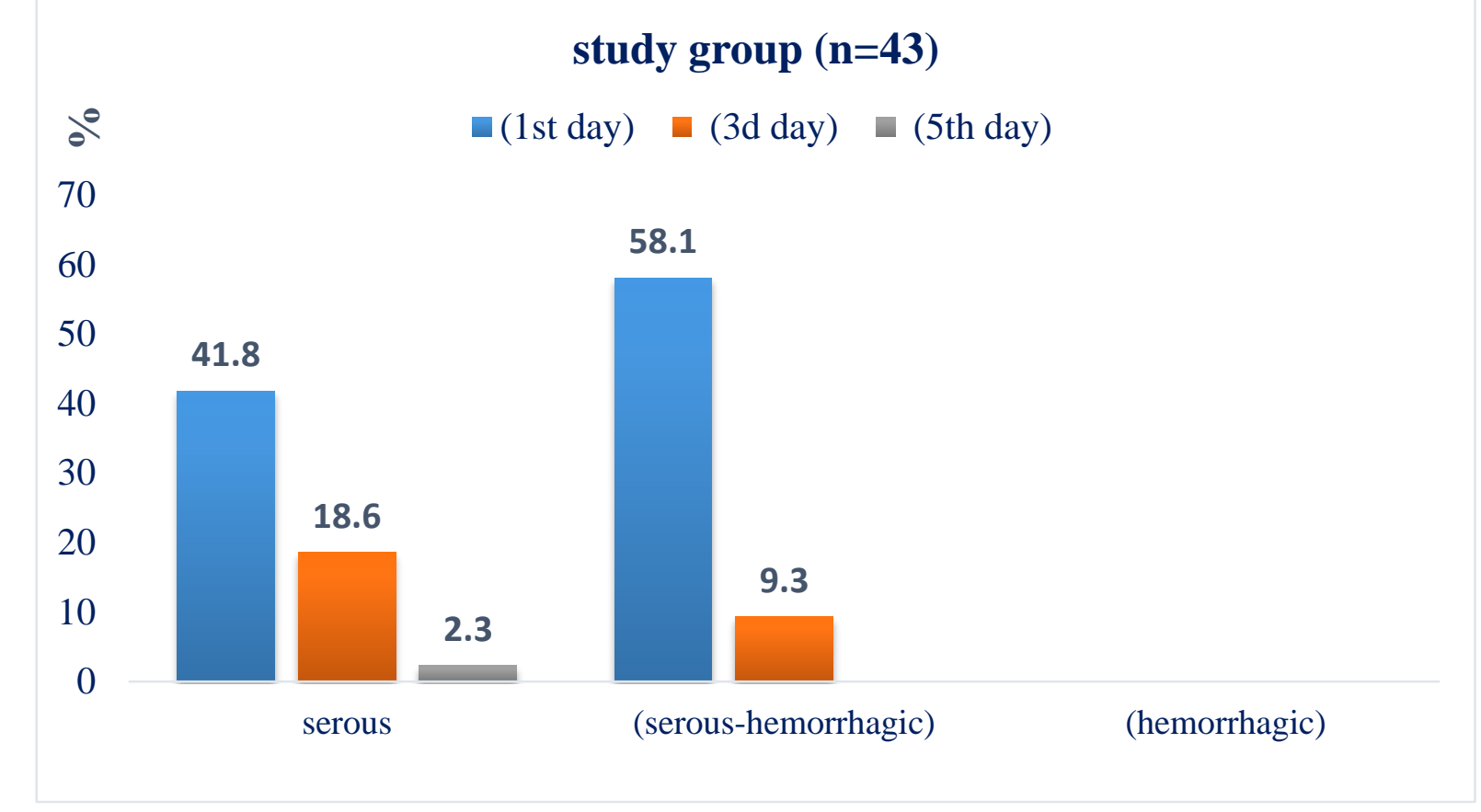

Figure 2. The type of the discharge from the drainage in the postoperative period in patients after traditional cholecystectomy in the study group.

As can be seen from Table 1, in both groups there was a statistically significant increase in the activity of ALT, AST and the level of bilirubin, while the change in the level of total protein was statistically insignificant. It should be noted that the correlation analysis did not reveal a connection between these indicators of the biochemical blood test with the duration of the operation, the age of the patients, and the duration of gallstone disease. In the control group, biochemical parameters reflect changes in liver function in response to damage during electrocoagulation of the gallbladder bed. In the main group, when hemostasis of the gallbladder bed was used, as shown in Table 1, a less noticeable increase in the activity of ALT, AST and the level of bilirubin was observed.

According to the established protocol, in the early postoperative period, the quantitative and qualitative characteristics of the drainage discharge were monitored, as well as the duration of the stay of the drainage tubes in the subhepatic space (Fig. 2-3). 


\section{control group $(n=45)$}

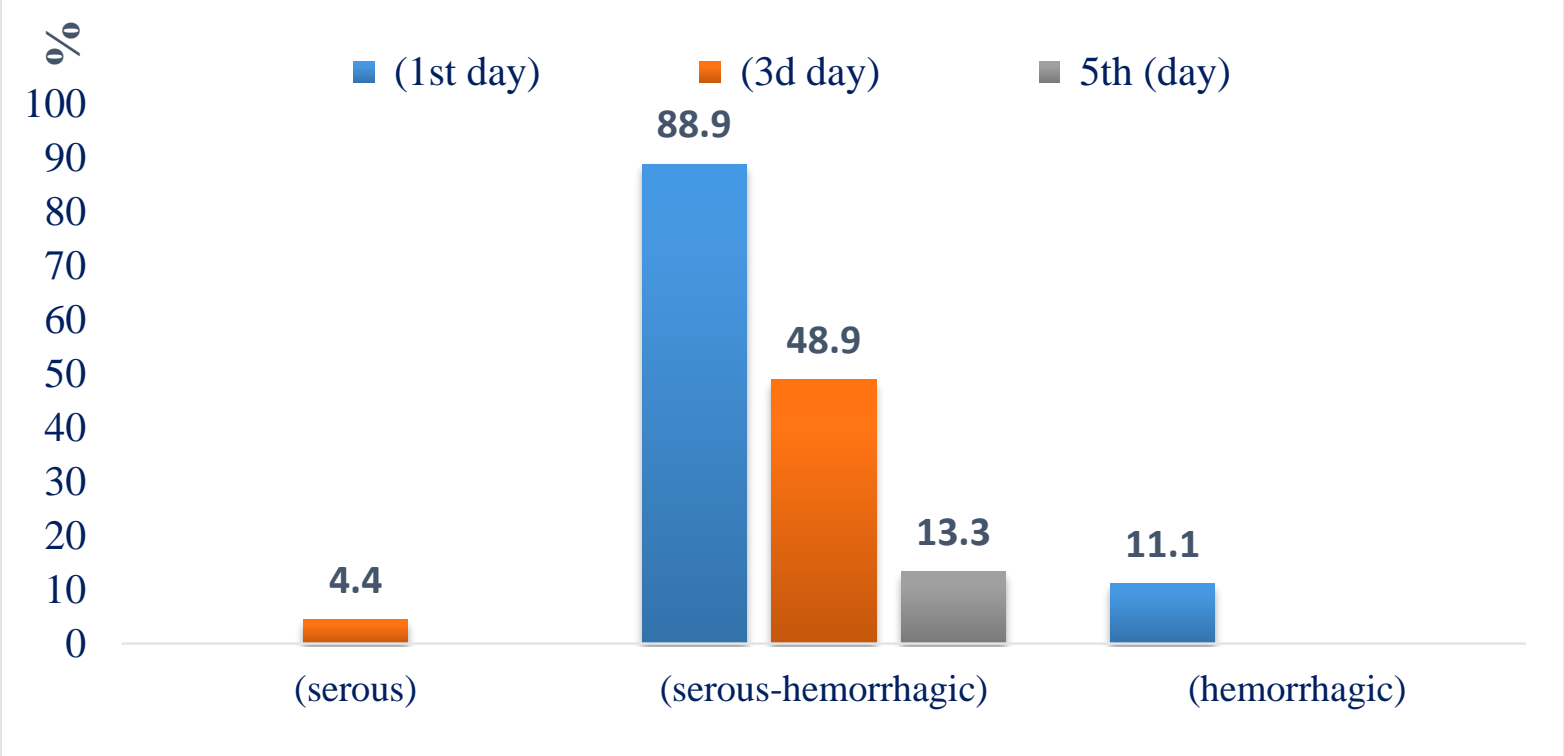

Figure 3. The type of the discharge from the drainage in the postoperative period in patients after traditional cholecystectomy in the study group.

In the main group, on the first day after the operation, there was a discharge of serous and serous-hemorrhagic (with a predominance of serous $(n=4)$, with a predominance of hemorrhagic ( $n=1)$ ) exudate). In this case, no hemorrhagic discharge was observed. On average, the volume of discharge from the drainage tubes per day was $20 \pm 2.4 \mathrm{ml}$. On the 3 rd day after the operation, discharge from the drainage of a serous nature was observed in 8 , and serous-hemorrhagic with a predominance of serous in 4 patients. On the 5 th day after the operation, only 1 patient had serous discharge up to $20 \mathrm{ml}$, the drainage was removed after ultrasound examination of the subhepatic space.

In the control group of patients, on the first day after the operation, there was a discharge of serous-hemorrhagic (serous-hemorrhagic ( $\mathrm{n}=$ $25)$, with a predominance of serous $(n=3)$, with a predominance of hemorrhagic $(n=12))$ and hemorrhagic $(n=5) \ldots$ On average, the volume of discharge from the drainage tubes per day was $45 \pm 8.3 \mathrm{ml}$. On the 3 rd day after the operation, serous discharge from the drainage was observed in 2, serous-hemorrhagic with a predominance of serous in 11 patients, seroushemorrhagic - in 7, serous-hemorrhagic with a predominance of hemorrhagic - in 4, and hemorrhagic discharge was not observed. On the 5th day after the operation, 2 patients showed serous-hemorrhagic with a predominance of serous, and 4 patients had serous-hemorrhagic discharge.

Thus, in the main group of patients who, during cholecystectomy, to stop bleeding from the 
gallbladder bed, used GEMOGUBKA, it was possible to significantly reduce the proportion of serous-hemorrhagic and hemorrhagic discharge from the drainage tube in comparison with the control group. It should be noted that tamponade of the gallbladder bed was not used in the main group for the purpose of hemostasis; moreover, no recurrence of bleeding from the gallbladder bed was observed.

In the control group, in one case, relaparotomy was performed on the 2nd day after the operation in connection with the ongoing hemorrhagic discharge up to $70-80 \mathrm{ml}$ per day. Bleeding was stopped by electrocoagulation with tamponation of the gallbladder bed.

It should be noted that in the main group of patients, the level of leukocytes returned to normal by $2-3$ days, body temperature by 2 days, and in the control group of patients - by 4-5 and 3-4 days, respectively. Sutures from the postoperative wound were removed in a polyclinic for 6-7 days. In the case of seroma formation or inflammation of the wound edges, the time spent on sutures increased. The average value of the postoperative bed / day in the control group was $6.3 \pm 2.06$ days, and in the main group, $4.5 \pm 0.78$ days.

To assess the degree of influence of the GEMOGUBKA powder on the prevention of the incidence of inflammatory complications of the operation area, we analyzed the dynamics of the temperature curve. We proceeded from the assumption that the accumulation of effusion, including blood, in the subhepatic space is a breeding ground for infection. In case of hyperthermia, the patients underwent chest X-ray, ultrasound examination of the subhepatic space and postoperative wound already on the 3 rd day.
When analyzing the results, significant differences in the temperature curves of the studied groups were obtained, starting from the end of the 2nd day of the postoperative period, characterized by a pyrogenic reaction in the control group, which correlates with the picture of sonographic examination of the subhepatic space in the studied groups in dynamics. Moderate hematoma of the bed in the control group was detected in $6.7 \%$, on the 3-4th day there was a tendency to suppuration and the formation of subhepatic abscesses in $2 \%$, which, despite the massive antibiotic therapy being carried out, required drainage in the control group. In 2 cases, the causes of hyperthermia in the control group were associated with tamponade of the gallbladder bed. After removing the tampons on the 5-6th day, the patient's temperature returned to normal. The end point of the comparative analysis of the main and control groups was the determination of the duration of the postoperative bed-day, which was $4.5 \pm 0.78$ and $6.3 \pm 2.06$ days, respectively.

\section{CONCLUSIONS}

1. Collagen hemostatic agent of domestic production GEMOGUBKA showed a rather high efficiency, while the hemostatic effect does not depend on the method of drug delivery to the bleeding surface of the gallbladder bed after open cholecystectomy. An effective hemostatic effect was manifested in $91.7 \%$ of cases.

2. GEMOGUBKA is capable of causing rapid hemostasis: on average, within $2.3 \pm 1.3$ minutes, and therefore it can be recommended in clinical practice with open cholecystectomy as a means for stopping and preventing bleeding from the gallbladder bed. 
3. The results obtained indicate the prospects of using the hemostatic drug GEMOGUBKA in emergency surgery of the biliary tract. The use of this biocomposition makes it possible to expand the arsenal of both the surgeon's hemostatic agents and to reduce the incidence of local inflammatory complications of the surgical site.

\section{REFERENCES}

1. Davydov A.A. The influence of electroexcision of the gallbladder on the course of the postoperative period and the functional state of the liver. 2002;2:34-38. (In Russ.)

2. Plotkin A.V., Poskrovskij E.Zh., Voronova G.V. i dr. Evaluation of the effectiveness of the hemostatic action of the drug "Hemoblock" in cavity and laparoscopic interventions. Mul'ticentrovye klinicheskie issledovanija. Vestnik sovremennoj klinicheskoj mediciny. 2015;8:56-61. (In Russ.)

3. Rahimov O.U., Muhammadsolih Sh.B. Surgical treatment of intra-abdominal bleeding after cholecystectomy, innovative technologies in medicine: a view of a young specialist. Materialy $\mathrm{V}$ Vserossijskoj nauchnoj konferencii molodyh specialistov, aspirantov, ordinatorov. 2019:69-70. (In Russ.)

4. Rahimov O.U., Tursumetov A.A., Zhamalov Zh.B. Intra-abdominal bleeding after various cholecystectomy options. Evrazijskij vestnik pediatrii. 2019;3:224-229. (In Russ.)

5. Sadykov R.A., Ismailov B.A., Kim O.V. NNew film coating made from cellulose derivatives for local hemostasis.
Novosti hirurgii. 2019;3:256-261. (In Russ.)

6. Tarkova A.R., Chernjavskij A.M., Morozov S.V. Local hemostatic material based on oxidized cellulose. Sibirskij nauchnyj medicinskij zhurnal. 2015;2:15-19. (In Russ.)

7. Cheng W., He J., Wu Y. et al. Preparation and characterization of oxidized regenerated cellulose film for hemostasis and the effect of blood on its surface. Cellulose. 2013;20(5):25472558. https://doi.org/10.1007/s10570013-0005-5

8. Brustia R., Granger B., Scatton O. An update on topical haemostatic agents in liver surgery: systematic review and metaanalysis. Journal of HepatoBiliary-Pancreatic Sciences. 2016;10(23):609-621. https://doi.org/10.1002/jhbp.389

9. Mueller G.R., PinedaT.J., XieH.X. et al. A novel sponge-based wound stasis dressing to treat lethal noncompressible hemorrhage. J. Trauma. 2012;73(Suppl. 1):134-139. https://doi.org/10.1097/ta.obo13e31826 $17 \mathrm{C} 3 \mathrm{C}$

10. Aday U. The effects of low-molecularweight-heparin administration on bleeding in elective laparoscopic cholecystectomy. Laparoscopic Endoscopic Surgical Science [Internet]. Kare Publishing; 2018; Available from: https://doi.org/10.14744/less.2017.53215

11. Szoka N, Yoo J. Use of MiniLaparoscopic Percutaneous Graspers During Laparoscopic Cholecystectomy. CSurgeries [Internet]. CSurgeries; 2017 Jun; Available from: https://doi.org/10.17797/201706072 
The American Journal of Medical Sciences and Pharmaceutical Research

(ISSN - 2689-1026)

Published: March 31, 2021 | Pages: 122-131

IMPACT FACTOR

2021: 5.64

Doi: https://doi.org/10.37547/TAJMSPR/Volume03Issue03-18

OCLC - 1121105510

12. Thakur S. Bleeding complications in laparoscopic cholecystectomy: Incidence, mechanisms, prevention and management. Journal of Minimal Access Surgery [Internet]. Medknow; 2011;7(3):200. Available from: https://doi.org/10.4103/0972-

9941.83516 